\title{
Primary aortogastric fistula: an extraordinary rare endoscopic finding in the setting of upper gastrointestinal bleeding
}
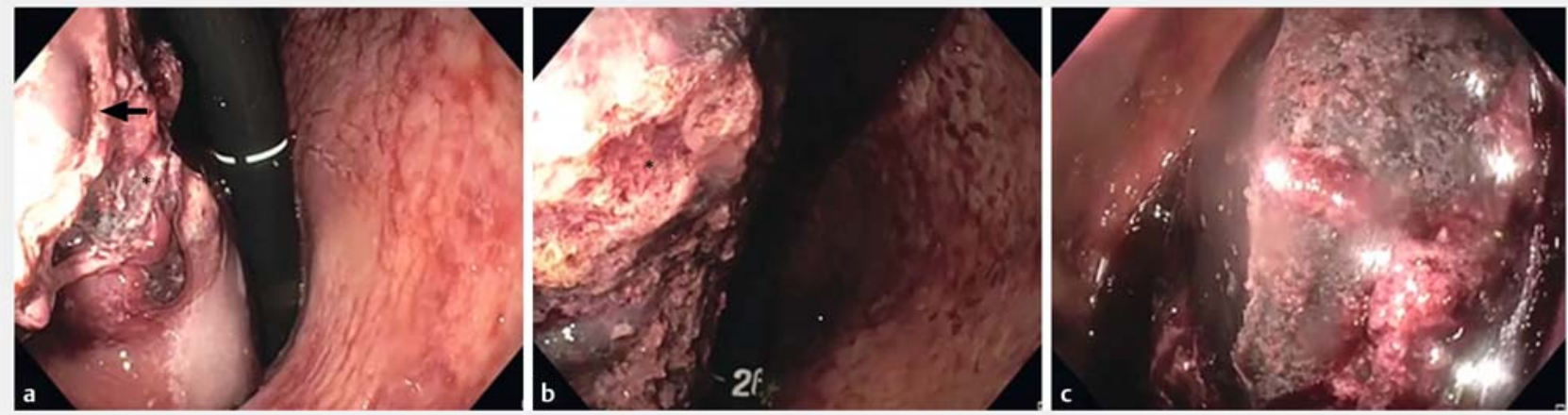

Fig. 1 Views during esophagogastroduodenoscopy showing: a, b on retroflexed view, an extrinsic bulging mass in the stomach (asterisk), partially covered by blood clots (arrow), originating from the fundus and extending to the posterior wall of the proximal body; c on frontal view, a large adherent blood clot.

A 78-year-old lady with a history of arterial hypertension and left upper lobectomy 4 months previously for stage IIB lung adenocarcinoma was admitted to our bleeding unit with severe anemia (hemoglobin level on admission $6.7 \mathrm{~g} / \mathrm{dL}$ ) and recent onset of melena. No hemodynamic instability was observed and, after a blood transfusion had been given, urgent esophagogastroduodenoscopy was performed with the patient under monitored anesthesia care. The retroflexion maneuver revealed an extrinsic pulsating bulging mass, partially covered by adherent large blood clots, originating from the fundus and extending to the posterior wall of the proximal body of the stomach. No active bleeding was noted ( $\triangleright$ Fig. 1; - Video 1).

Emergent computed tomography angiography revealed a ruptured thoracoabdominal aortic aneurysm (TAAA) within a $7 \times 6-\mathrm{cm}$ periaortic hematoma that was compressing the gastric wall. No contrast extravasation into the stomach was noted; however, the tissue planes between the aorta and the stomach appeared obliterated ( $\mathbf{F i g} \mathbf{2}$ ). The TAAA involved the proximal part of the celiac artery and was located around $12 \mathrm{~mm}$ above the origin of the superior mesenteric artery

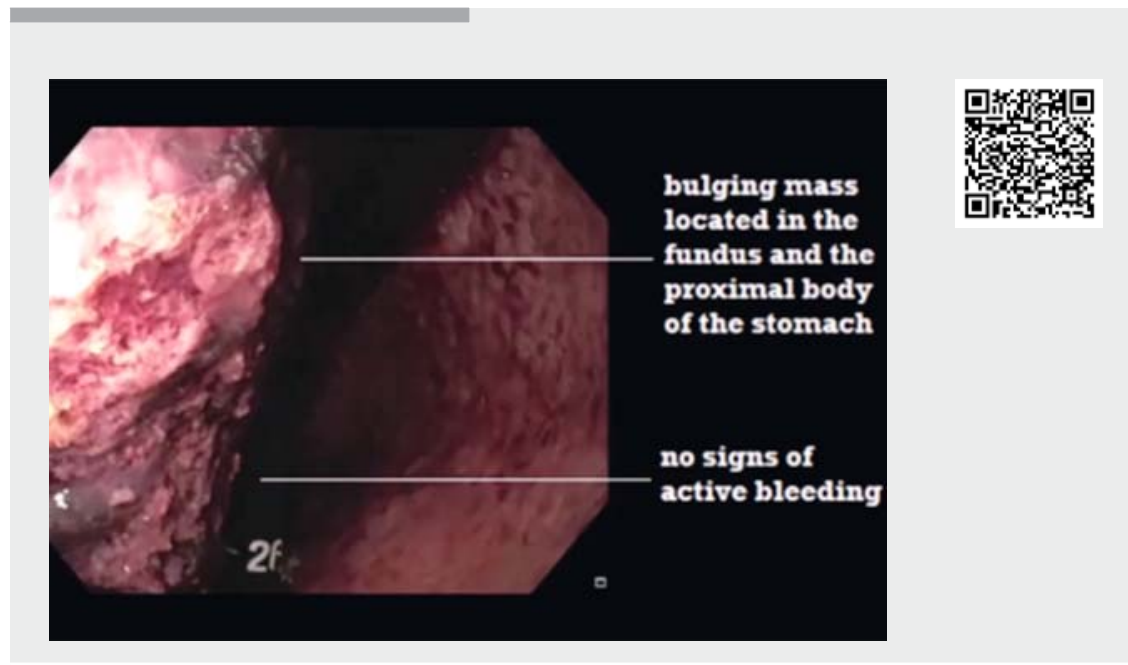

$\nabla$ Video 1 Diagnosis and management of a primary aortogastric fistula in the setting of acute upper gastrointestinal bleeding.

$(\mathrm{SMA})(\triangleright$ Fig. 3). The patient was immediately transferred to the surgical theatre. After prompt multidisciplinary evaluation, endovascular stent grafting was successfully performed just above the SMA ostium. A subsequent gastric surgical repair was planned after clinical stabilization had been achieved. Unfortunately, the patient succumbed on postoperative day 2 from multiorgan failure.
Primary aortoenteric fistulas are communications between the native aorta and any part of the gastrointestinal (Gl) tract, with a reported incidence of $0.07 \%$ [1]. A primary aortogastric fistula (PAGF) is an extraordinary location for this [1], with an extremely high mortality [2]. To date, endoscopic images of PAGFs have only been provided in three case reports [35]. This is the first video to show with ex- 


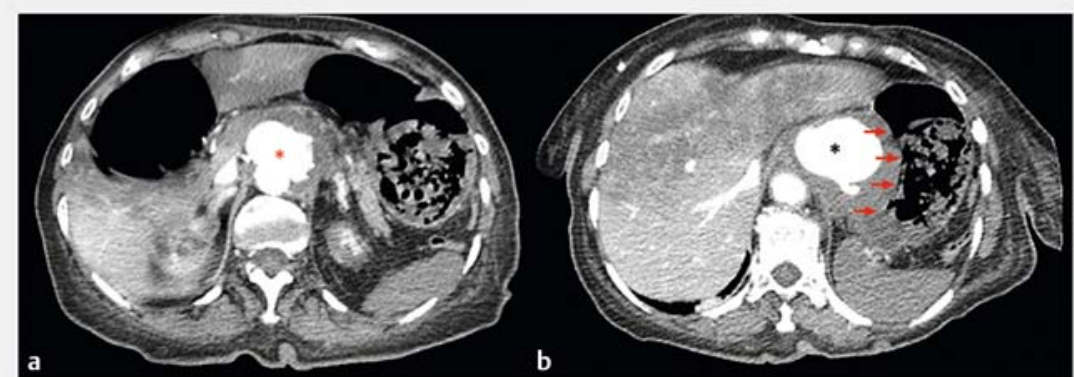

- Fig. 2 Arterial phase contrast-enhanced computed tomography images showing: a a contained rupture of a thoracoabdominal aortic aneurysm (red asterisk); $\mathbf{b}$ a periaortic hematoma (black asterisk) compressing the posterior gastric wall with loss of the tissue planes between the aorta and the stomach (arrows).

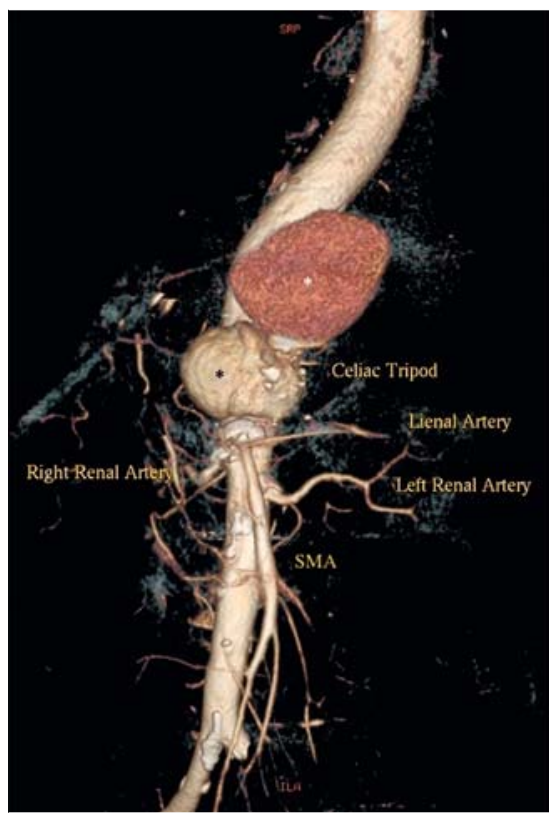

Fig. 3 Three-dimensional computed tomography angiography showing the ruptured thoracoabdominal aortic aneurysm (black asterisk), contained within a periaortic hematoma (white asterisk) and located around $12 \mathrm{~mm}$ above the ostium of the superior mesenteric artery (SMA).

ceptional clarity the endoscopic appearance of a PAGF. GI endoscopists should be aware of this life-threatening, albeit extremely rare, cause of Gl bleeding in order to provide early diagnosis and treatment.

Endoscopy_UCTN_Code_CCL_1AB_2AD_3AZ

\section{Competing interests}

The authors declare that they have no conflict of interest.

The authors

Alberto Martino ${ }^{1}$, Raffaele Bennato ${ }^{1}$, Gaspare Oliva $^{2}$, Armando Pontarelli ${ }^{3}$, Desiree Picascia ${ }^{1}$, Luigia Romano ${ }^{2}$, Giovanni Lombardi ${ }^{1}$

1 Department of Gastroenterology and Digestive Endoscopy, AORN “Antonio Cardarelli”, Napoli, Italy

2 Department of General and Emergency Radiology, AORN “Antonio Cardarelli”, Napoli, Italy

3 Department of Vascular Surgery, AORN “Antonio Cardarelli", Napoli, Italy

\section{Corresponding author}

\section{Alberto Martino, MD}

Gastroenterology and Digestive Endoscopy, AORN Antonio Cardarelli, Via Antonio Cardarelli 9, 80131 Naples, Italy Fax: +39-081-7472232 alberto-martino@libero.it

[1] Saers SJF, Scheltinga MRM. Primary aortoenteric fistula. Br J Surg 2005; 92: 143-152

[2] Kougias P, Baltazar U, Battle WJ et al. Primary aortogastric fistula after Nissen fundoplication: a case report and review of pertinent literature. Vasc Endovascular Surg 2003; 37: 135-139

[3] Wei XQ, Song L, Zhang XS et al. Endovascular stent graft repair of aortogastric fistula caused by peptic ulcer after esophagectomy: A case report. Medicine (Baltimore) 2017; 96: e8959

[4] Chotai HS, Finch G, Thomas D et al. Successful management of an aorto-gastric fistula occurring 15 years after oesophagectomy with covered aortic stent graft placement followed by open surgery. J Surg Case Rep 2018; 2018: rjy019

[5] Ong J, Swift C, Al-Naeeb Y. Aortogastric fistula: A rare glimpse of catastrophe. Clin Gastroenterol Hepatol 2019. doi:10.1016/j. cgh.2019.03.033

Bibliography

Endoscopy 2021; 53: E60-E61

DOI 10.1055/a-1180-7701

ISSN 0013-726X

published online 19.6.2020

(c) 2020. Thieme. All rights reserved.

Georg Thieme Verlag KG, Rüdigerstraße 14,

70469 Stuttgart, Germany

\section{ENDOSCOPY E-VIDEOS}

https:|/eref.thieme.de/e-videos

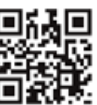

Endoscopy E-Videos is a free access online section, reporting on interesting cases and new techniques in gastroenterological endoscopy. All papers include a high quality video and all contributions are freely accessible online.

This section has its own submission website at

https://mc.manuscriptcentral.com/e-videos 